УДК 619:616-008.61:636.5

https://doi.org/10.32634/0869-8155-2020-339-6-25-28

Тип статьи: Краткий обзор

Type of article: Brief review

\section{Явников Н.В.}

ФГБОУ ВО «БелгородскИЙ ГАУ»

308503, Белгородская обл., п. Майский,

ул. Вавилова, 1

E-mail: iavnikov@belfarma.com

Ключевые слова: тепловой стресс у птицы, борьба с тепловым стрессом птицы, Комплисид, Либекрин, Бутацифол.

Для цитирования: Явников Н.В.

Стратегия борьбы с тепловым стрессом в птицеводстве. Аграрная наука. 2020; 339 (6): 25-28.

https://doi.org/10.32634/0869-8155-2020-339-6-25-28

Конфликт интересов отсутствует

\section{Nazar V. Yavnikov}

Belgorod State Agricultural University, "Belfarmacom" Ltd.

Vavilova st. 1, Mayskiy vil., Belgorodskaya obl. 308503, Russia

E-mail: iavnikov@belfarma.com

Key words: heat stress in poultry, deal with heat stress in poultry, Complicid, Libecrin,

Butacyfol.

For citation: Yavnikov N.V. The strategy for dealing with heat stress in poultry. Agrarian Science. 2020; 339 (6): 25-28. (In Russ.)

https://doi.org/10.32634/0869-8155-2020-339-6-25-28

There is no conflict of interests

\section{Стратегия борьбы с тепловым стрессом в птицеводстве}

\section{PEЗЮME}

Актуальность. В летний период тепловой стресс становится одной из серьёзнейших проблем промышленного птицеводства. По своей сути тепловой стресс является дисбалансом между поступлением тепла из окружающей среды и выделением энергии организмом птицы. Данная патология приносит ощутимые экономические потери и может стать причиной массового падежа птицы.

Материал и методы. В статье рассмотрен комплекс мероприятий по минимизации негативного влияния экстремально высоких температур окружающей среды на птицу.

Результаты. Для борьбы с негативными последствиями теплового стресса предложено снижать рН питьевой воды добавлением комплекса органических кислот Комплисид, а для повышения концентрации нутриентов в рационе птицы рекомендовано проводить медикацию препаратами Либекрин и Бутацифол.

\section{The strategy for dealing with heat stress in poultry}

\section{ABSTRACT}

Relevance and methods. In the summer period heat stress becomes one of the most serious problems of industrial poultry farming. At its core heat stress is an imbalance between the flow of heat from the environment and the release of energy by the bird's body. This pathology brings tangible economic losses and can cause a massive mortality of the poultry. The article describes a set of measures to minimize the negative impact of extremely high ambient temperatures on the poultry.

Results. To deal with the negative effects of heat stress, it was proposed to lower the $\mathrm{pH}$ of drinking water by adding the Complicid's organic complex of acids, and to increase the concentration of nutrients in the poultry diet it was recommended to carry out medication with Libecrin and Butacyfol. 


\section{Введение}

Тепловой стресс вызывает поведенческие, физиологические и иммунологические изменения в организме птицы, что отрицательно сказывается на ее здоровье, потреблении корма, продуктивности и качестве продукции. В результате птицеводческие хозяйства несут значительные финансовые потери. Тяжесть проявления теплового стресса зависит от внешних (состав рациона, вода, система содержания, плотность посадки, влажность воздуха, скорость движения воздуха и т. д.) и внутренних (вид, порода, возраст, физиологическое состояние птицы и т. д.) факторов.

По своей сущности тепловой стресс - это воздействие высоких температур на организм птицы, которое влечет за собой ряд негативных изменений во всех органах и системах организма. С точки зрения практиков, наиболее значимыми последствиями перегрева являются изменение теплового обмена птицы, развитие респираторного алкалоза, снижение эффективности усвоения питательных веществ в желудочно-кишечном тракте и оксидативный стресс, поскольку именно эти нарушения становятся причиной массового отхода птицы и снижения продуктивности.

Способы борьбы с неблагоприятным воздействием высоких температур окружающей среды можно разделить на несколько групп:

\section{Снижение температуры воздуха в птичнике}

Для снижения температуры воздуха в птичнике рекомендуют увеличивать скорость движения воздуха до 2,0-2,5 м/с и количество свежего воздуха до 6-7 м3 на 1 кг живой массы в час, что создает у птицы ощущение прохлады. При этом использование туннельной вентиляции позволяет добиться максимальных конвективных теплопотерь, особенно в условиях высокой влажности. В хозяйстве должна быть запасная система электропитания на случай перебоев в жаркое время. Необходимо оборудовать помещение системой испарительного охлаждения, при которой воздух проходит через бумажные прокладки, смоченные водой, и уже охлажденный попадает в птичник. C ее помощью даже при температуре внешней среды выше $35-38{ }^{\circ} \mathrm{C}$ в птичнике можно удерживать температуру $24-28{ }^{\circ} \mathrm{C}$ и ниже. Однако следует учитывать, что чем выше влажность, тем ниже эффект испарительного охлаждения. Также эффективно использование в строительстве птичников теплоизолирующих, светоотражающих кровельных материалов (например алюминиево-пластиковой фольги), орошения крыши холодной водой и т. п.

Вышеуказанные мероприятия снижают патогенное воздействие высокой температуры на организм птицы. Но при недостаточной эффективности работы системы кондиционирования воздуха применение в строительстве птичника материалов с высокой теплопроводностью требуется проведения реконструкции, что требует значительных материальных затрат и времени.

\section{Селекционно-племенная работа}

Перспективным направлением профилактики и смягчения последствий теплового стресса может считаться повышение теплоустойчивости птицы посредством селекционно-племенной работы. Заслуживает внимания использование в селекции птицы генов, способствующих термоустойчивости, таких как ген голошейности $(\mathrm{Na})$ и ген курчавости оперения (F). Данное направление заслуженно считается перспективным, но при экстремально высоких температурах окружающей среды мероприятия необходимо предпринимать немедленно. Манипуляции с птицей при тепловом стрессе. При манипуляциях с птицей во время теплового стресса необходимо соблюдать следующие правила: нельзя беспокоить ее в наиболее жаркий период дня; вакцинацию, перевозку поголовья с площадки выращивания в птичники для взрослой птицы следует проводить в прохладное время суток (ранним утром или поздним вечером); при вакцинации с помощью питьевой воды не прекращать ее подачу; исключить вакцинацию спреем; проводить профилактику бактериальной инфекции (при дыхании открытым ртом не происходит фильтрации воздуха через носовые каналы, в результате в организм попадает вторичная бактериальная инфекция, которая повышает отход птицы). Соблюдение вышеуказанных правил позволяет предотвратить повышенный отход, но не позволит повысить продуктивность птицы, испытывающий тепловой стресс.

Исходя из вышесказанного, основными направлениями работы по снижению последствий гипертермии являются правильная организация водопоения, а также кормовые и медикаментозные коррекции.

Поение должно осуществляется свежей прохладной водой, нагревшуюся воду в поилках периодически спускают и заполняют новой, более холодной. Оптимальная температура воды в жаркий период $12-15^{\circ} \mathrm{C}$. Доказано, что снижение температуры питьевой воды для птицы до указанных пределов понижает температуру тела на $0,5^{\circ} \mathrm{C}$.

Подкисление питьевой воды с помощью комплекса различных органических (муравьиная, уксусная, лимонная, фумаровая и др.) кислот способствует санации полости рта, носа и всей пищеварительной системы птицы, благоприятствуют полезным бактериям, подавляет патогенные микроорганизмы (сальмонеллы, Escherichia coli, плесневые и дрожжевые грибы) в желудочно-кишечном тракте. Кислотная среда также помогает выработке ферментов поджелудочной железы и способствует превращению пепсиногена в пепсин, затормаживает прохождение химуса через желудочно-кишечный тракт. В условиях высокой температуры необходимо ещё более тщательно проводить очистку и обеззараживание воды и системы поения.

\section{Препарат: Комплисид}

Рекомендуем для подкисления питьевой воды, а также дезинфекции и очистки системы водопоения применять Комплисид - комплекс органических кислот (муравьиная, уксусная, молочная и сорбиновая).

Дозировка: 200-500 мл на 1000 л воды (уровень $\mathrm{pH}$ раствора не должен превышать 4,5), продолжительность курса 3-5 дней.

Коррекция кормления птицы в условиях жары осуществляется по двум направлениям: изменение кратности кормления и количества корма (организационные мероприятия) и изменение состава и структуры корма.

Применяют специальные режимы кормления. Рекомендуют ограничивать птицу в кормах за 46 ч до начала теплового стресса. За это время остатки корма выводятся из кишечника, и прирост тепла, связанный с потреблением корма в жаркий период дня, снижается. Целесообразно сдвинуть основные кормления на утреннее и вечернее время или использовать «принцип ночного кормления».

Изменение структуры и состава корма. Предпочтение следует отдать гранулированным комбикормам, поедание корма в виде гранул занимает на треть меньше 
времени по сравнению с таким же количеством рассыпанного корма и позволяет птице экономить около 6\% энергии, что может благотворно сказаться на снижении теплопродукции организма. Кроме того, гранулирование повышает физическую плотность корма, обеспечивая большее потребление питательных веществ.

Считается, что суточную норму питательных веществ в условиях теплового стресса необходимо поддерживать за счет повышения плотности корма пропорционально снижению его потребления.

Например, если ожидается снижение потребления корма на 10\%, содержание всех питательных веществ (включая витамины, минеральные соединения, микроэлементы) необходимо повысить на 10\%. Положительные результаты дает изменение в энергии кормов пропорции жиров и углеводов, то есть соотношения эффективной и обменной энергии. Необходимо повышать содержание аминокислот в корме (при потреблении несбалансированных по аминокислотному составу кормов птица производит больше тепла в расчете на 1 г потребленного корма, кроме того, при тепловом стрессе значительно увеличивается расход лизина и серосодержащих аминокислот), а также антиокислителей.

Однако применение этой стратегии иногда ограничено возможностями производства. Так, не всегда приемлемо добавление к кормосмеси более 6-8\% жира. Кроме того, дозы некоторых кормовых добавок нельзя изменять, не зная, как это подействует на здоровье птицы. Во многих случаях снижение потребления корма настолько значительно, что его невозможно компенсировать за счет повышения концентрации питательных веществ.

Для снижения производства эндогенного тепла у птицы при тепловом стрессе рекомендуют применять два рациона: в жаркий период суток - рацион с повышенным (на 4-5\%) содержанием жира и пониженным (на 2-4\%) количеством сырого протеина, в прохладный период - рацион с пониженным содержанием жира и повышенной долей сырого протеина.

На практике возможность применения этого метода ограничена ресурсами кормовой базы, также в большинстве хозяйств будет затруднительно в течение суток менять комбикорма.

Поэтому в практике современного птицеводства для борьбы со стрессами широко используются различные препараты, выпаиваемые с водой. Для достижения положительного эффекта такие препараты должны содержать в своём составе целый комплекс нутриентов (антиоксиданты, гепатопротекторы, осмогены, электролиты органические кислоты).

Для снижения патогенного воздействия на организм птицы высоких температур рекомендуем применять препараты либекрин и бутацифол.

\section{Препарат: Либекрин}

Либекрин - кормовая добавка для повышения резистентности и продуктивности сельскохозяйственной птицы. Обладает антистрессовым действием, гепатопротекторным действием, стимулирует пищеварение и обмен веществ, является осмопротектором.

Состав:

- бетаин;

- лизин;

- метионин;

- лимонная кислота;

- фумаровая кислота, янтарная кислота, цинк;

- лимонная кислота

- натрий хлорид;
- калий хлорид;

- вспомогательные вещества: сорбит; пропиленгликоль и растворитель.

Биологически активные вещества, входящие в состав данного препарата, обладают следующим действием:

Бетаин - триметильное производное глицина - является осмопротектором (удерживает воду в клетках), улучшает состояние кишечного эпителия, предупреждает накопление липидов в печени, улучшает перевариваемость и усвоение жиров корма, стимулирует пищеварение. Традиционно используется в качестве гепатопротекторного и метаболического средства.

Лизин и метионин - незаменимые «лимитирующие» аминокислоты. Обладают антистрессовыми свойствами, снижают тепловую нагрузку на организм.

Лизин - входит в состав практически всех белков, необходим для роста, восстановления тканей, производства антител, гормонов, ферментов, альбуминов. Лизин улучшает усвоение кальция из крови и транспорт его в костную ткань, оказывает противовирусное действие.

Метионин - серосодержащая $\alpha$-аминокислота, служит в организме донором метильных групп при биосинтезе холина, адреналина и др., а также является источником серы при биосинтезе цистеина, оказывает некоторое липотропное действие, повышает синтез холина, лецитина и других фосфолипидов, в некоторой степени способствует снижению содержания холестерина в крови и улучшению соотношения фосфолипиды/холестерин, уменьшению отложения нейтрального жира в печени и улучшению функции печени.

Цинк - необходим для метаболизма витамина E, который является предшественником половых гормонов и включается в продукцию тестостерона, участвует в синтезе разных анаболических гормонов в организме, включая инсулин, тестостерон и гормон роста, а также обладает вяжущими свойствами.

Соли калия и натрия поддерживают водно-солевой баланс организма. Основная функция натрия - в поддержании осмотического давления внеклеточных жидкостей. Калий же - внутриклеточный катион. Калий и натрий всегда находятся в свободном ионном состоянии, участвуют в проводимости нервных импульсов. Калий задействуется также в эритроцитах в процессе переноса кислорода гемоглобином, служит кофактором ферментов.

Лимонная, янтарная и фумаровая кислоты - одни из важнейших участников цикла трикарбоновых кислот (цикла Кребса), ключевого этапа дыхания всех клеток.

Либекрин применяют перорально с водой для поения ежедневно в течение 5-7 дней, возможно продления курса до 21 дня, в дозе 0,2-0,5 л на 1000 л воды для поения.

\section{Препарат: Бутацифол}

Бутацифол - общеукрепляющая и тонизирующая кормовая добавка, применяется для нормализации метаболических и регенеративных процессов у сельскохозяйственной птицы, для повышения продуктивности.

Состав:

- бутафосфан;

- цианокобаламин (Витамин В12);

- фолиевая кислота (Витамин В9).

Бутафосфан способствует улучшению функции печени, в том числе по обезвреживанию микотоксинов, стимулирует метаболические процессы, повышает двигательную активность гладкой мускулатуры. 
Цианокобаламин (витамин $\mathrm{B}_{12}$ ) активизирует процессы кроветворения, синтеза нуклеиновых кислот, восстанавливает до нормы уровень лимфоцитов-супрессоров, участвует в синтезе метионина, способствует образованию гликогена, мобилизует запасы энергии, необходимые для образования дезоксирибозы и синтеза ДНК.

Фолиевая кислота (витамин $\mathrm{B}_{9}$ ) - необходим для нормального созревания мегалобластов и образования нормобластов. Стимулирует эритропоэз, участвует в синтезе аминокислот (в том числе глицина, метионина), нуклеиновых кислот, пуринов, пиримидинов, в обмене холина, гистидина.

Бутацифол применяют перорально с водой для поения ежедневно в течение 4-5 дней в дозе 0,5-3,0 л на 1000 л воды для поения, при необходимости курс можно повторить через 5-7 дней.

\section{ЛИТЕРАТУРА}

1. Фисинин В.И., Кавтарашвили А.Ш. Стресс у птицы. Методы и способы профилактики и смягчения (обзор). Сельскохозяйственная биология. 2015;50(4):431-443.

2. Teeter R.G., Smith M.O., Owens F.N. et al. Chronic heat stress and respiratory alkalosis: occurrence and treatment in broiler chickens. Poultry Science. 1985;(64):1060-1064.

3. Кавтарашвили, А.Ш., Колокольникова Т.Н. Методы смягчения стресса в птицеводстве. Феникс-Кус (Казахстан). 2010; (8):11-18.

4. Yahav S., Straschnow A., Luger D., et al. Ventilation, sensible heat loss, broiler energy, and water balance under harsh environmental conditions. Poult. Sci. 2004;(83):253-258.

5. Маилян Э.С. Микроклимат в птицеводстве. Профилактика теплового стресса. Зооиндустрия. 2007;(9):8-13.

6. Deeb N., Cahaner A. Genotype-by-temperature interaction with broiler genotypes differing in growth rate. 1 . The effects of high ambient temperature and naked-neck genotype on lines differing in genetic background. Poult. Sci. 2001;(80):695-702.

7. Raju M.V., Sunder G.S., Chawak M.M. et al. Response of naked neck (Nana) and normal (nana) broiler chickens to dietary energy levels in a subtropical climate. Br. Poult. Sci. 2004;(45):186-193.

8. Михайловская, О., Медведенко А., Степаненко В. Температурный стресс у кур несушек в жаркий период года [Электронный ресурс]. Hy-Line International. 2010. - режим доступа: http://www.hyline.com.

9. Кавтарашвили А. Качество воды - важнейшее условие для здоровья и продуктивности птицы. Птицеводство. 2013;(3):17-25.

10. Gutierrez W.M., Min W., Chang H.H. Effects of chilled drinking water on performance of laying hens during constant high ambient temperature. Asian Australasian Journal of Animal Sciences. 2009;22(5):694-699.

11. Фисинин В.И., Кавтарашвили А.Ш., Колокольникова Т.Н. Современная стратегия борьбы с тепловым стрессом птицы. Ветеринария. 2014;(7):9-14.

12. Кузнецов Н.В. Аминокислотное и энергетическое питание мясных кур в условиях жаркого климата: автореферат дис. на соискан. учен. степени канд. сельскохоз. наук (06.02.02) Сергиев Посад, 1997. 18 с.

13. Маркин, Ю.В., Спиридонов Д.Н., Зевакова В.К., Полунина С.В. Тепловой стресс: теория и практика. Комбикорма. 2011;(4):59-60.

14. Gous R.M., Morris T.R. Nutritional interventions in alleviating the effects of high temperatures in broiler production. World's Poult. Sci. J. 2005;(61):463-475.

15. Daghir, N.J. Nutritional strategies to reduce heat stress in broilers and broiler breeders. Lohmann Information. 2009;(44):615.

\section{OБ ABTOPE:}

Явников Назар Валентинович, кандидат ветеринарных наук

\section{REFERENCES}

1. Fisinin V.I., Kavtarashvili A.Sh. Stress in a bird. Methods and methods of prevention and mitigation (review). Agricultural biology. 2015;50(4):431-443. (In Russ.)

2. Teeter R.G., Smith M.O., Owens F.N. et al. Chronic heat stress and respiratory alkalosis: occurrence and treatment in broiler chickens. Poultry Science. 1985;(64):1060-1064.

3. Kavtarashvili, A.Sh., Kolokolnikova T.N. Stress mitigation techniques in poultry farming. Phoenix-Kus (Kazakhstan). 2010;(8):11-18. (In Russ.)

4. Yahav S., Straschnow A., Luger D., et al. Ventilation, sensible heat loss, broiler energy, and water balance under harsh environmental conditions. Poult. Sci. 2004;(83):253-258.

5. Mayilyan E.S. Microclimate in poultry farming. Prevention of heat stress. Zoo industry. 2007;(9):8-13. (In Russ.)

6. Deeb N., Cahaner A. Genotype-by-temperature interaction with broiler genotypes differing in growth rate. 1 . The effects of high ambient temperature and naked-neck genotype on lines differing in genetic background. Poult. Sci. 2001;(80):695-702.

7. Raju M.V., Sunder G.S., Chawak M.M. et al. Response of naked neck (Nana) and normal (nana) broiler chickens to dietary energy levels in a subtropical climate. Br. Poult. Sci. 2004;(45):186-193.

8. Mikhailovskaya, O., Medvedenko A., Stepanenko V. Temperature stress in laying hens in the hot season [Electronic resource]. Hy-Line International. 2010. - access mode: http:// www.hyline.com. (In Russ.)

9. Kavtarashvili A. Water quality is an essential condition for the health and productivity of poultry. Poultry farming. 2013;(3):17-25. (In Russ.)

10. Gutierrez W.M., Min W., Chang H.H. Effects of chilled drinking water on performance of laying hens during constant high ambient temperature. Asian Australasian Journal of Animal Sciences. 2009;22(5):694-699.

11. Fisinin V.I., Kavtarashvili A.Sh., Kolokolnikova T.N. A modern strategy for controlling heat stress in birds. Veterinary Medicine. 2014;(7):9-14. (In Russ.)

12. Kuznetsov N.V. Amino acid and energy nutrition of meat chickens in a hot climate: abstract of dis. on the competition. scientist degrees of cand. agricultural farm. Sciences (06.02.02) Sergiev Posad, 1997. 18 p. (In Russ.)

13. Markin Yu.V., Spiridonov D.N., Zevakova V.K., Polunina S.V. Heat stress: theory and practice. Compound feed. 2011;(4):5960. (In Russ.)

14. Gous R.M., Morris T.R. Nutritional interventions in alleviating the effects of high temperatures in broiler production. World's Poult. Sci. J. 2005;(61):463-475.

15. Daghir, N.J. Nutritional strategies to reduce heat stress in broilers and broiler breeders. Lohmann Information. 2009;(44):615.

\section{ABOUT THE AUTHORS:}

Nazar V. Yavnikov, Candidate of Science in Veterinary 